\title{
Branch retinal artery occlusion secondary to high-altitude exposure and diabetic retinopathy: a case report
}

\author{
Xue Feng ${ }^{1,2}$, Luping Wang ${ }^{1}$, Haiwei Wang ${ }^{3}$, Hong Qi ${ }^{4}$, Jianqiang Zhang ${ }^{2}$ and Yanling Wang ${ }^{1 *}$
}

\begin{abstract}
Background: To report a case of branch retinal artery occlusion (BRAO) secondary to high-altitude exposure and diabetic retinopathy (DR), and to characterize the retinal changes before and after hyperbaric oxygen (HBO) treatment.

Case presentation: We present a case of a 42-year-old man with DR who travelled to Tibet (in China, $3800 \mathrm{~m} /$ $12467 \mathrm{ft}$. above mean sea level). The day after the end of his journey, the patient presented with acute, painless visual loss and visual field loss in his left eye. He was then diagnosed with BRAO, which is an acute blockage of blood flow. After HBO treatment, visual acuity and visual field were improved.

Conclusions: High-altitude exposure and DR may be considered as relevant risk factors for BRAO. The ophthalmologist should be aware that the BRAO might be a rare presenting sign of high-altitude retinopathy (HAR), particularly in patients with DR. HBO treatment can be considered as a choice for ophthalmologists on treatment against BRAO.
\end{abstract}

Keywords: Branch retinal artery occlusion, High altitude, Diabetic retinopathy, Hyperbaric oxygen

\section{Background}

Travelling to altitudes of $2500 \mathrm{~m}$ or more may put people at risk of high-altitude retinopathy (HAR), which is an acquired vascular retinopathy characterized by dilated veins and retinal hemorrhages [1]. Usually, vision is not affected by HAR unless it involves the macula [2]. HAR tends to resolve spontaneously, and in most cases, treatment is not required; nevertheless, systemic altitude illness needs to be treated. The mechanism of HAR remains unknown [3]. It has been hypothesized that decreased arterial oxygen results in vascular incompetence [4]; however, it remains unclear what happens to the retina of patients with diabetic retinopathy (DR) exposed to high altitude. Branch retinal artery occlusion (BRAO) secondary to high-altitude exposure is uncommon in

\footnotetext{
*Correspondence: doctorwyl2020@sina.com

'Department of Ophthalmology, Beijing Friendship Hospital, Capital Medical University, NO.95 Yong'an Road, Xicheng District, Beijing 100050, China

Full list of author information is available at the end of the article
}

clinical practice, particularly in patients with DR. Herein, we reported on a peculiar case of BRAO involving concurrent high-altitude exposure and DR without other causative agents. In addition, we summarized the characteristic features of the changes in the retina before and after hyperbaric oxygen $(\mathrm{HBO})$ treatment.

\section{Case presentation}

A 42-year-old man (lowlander, Beijing, China, $43.5 \mathrm{~m} /$ $142.7 \mathrm{ft}$. above mean sea level) presented with acute, painless visual loss and visual field loss in his left eye. The patient travelled to Tibet before the onset of symptoms when he took 1 day to ascend to the high altitude by car. He spent 1 week at high altitude before the descent back, which also took him 1 day by car. The complaints began at a low altitude after the end of his journey. The patient had type II diabetes, which was controlled by insulin for 10 years. He also used metformin for some time. The patient underwent binocular 
subtotal panretinal photocoagulation for the treatment of DR at 3 months before his journey. The patient did not have any other ocular treatments, such as intravitreal injections or intraocular surgery. According to the severity of DR from the description of the patient, the left eye was slightly worse than the right eye. Blood glucose was not monitored during the high-altitude journey. The patient had no history of smoking, hypertension, and hypercholesterolemia. Multiple carotid atherosclerotic plaques were shown by the Doppler examination. Increased blood cell counts for white blood cell (WBC), red blood cell (RBC), hemoglobin (HB) and packed cell volume (PCV) were revealed by hematologic examination. Decreased prothrombin time (PT) and increased prothrombin time activity were revealed by hematologic examination. All of the systemic examination parameters are shown in Table 1.

The best-corrected visual acuity (BCVA) in the right and the left eye were 20/25 and 20/40 (Snellen Chart), respectively. Non-contact intraocular pressure was 17 $\mathrm{mmHg}$ in the right eye and $18 \mathrm{mmHg}$ in the left eye. Anterior segment examinations were normal in both eyes. Ophthalmoscopy revealed hemorrhages, cotton wool spots, and laser spots in both eyes. Superficial retinal whitening inferior to the fovea along the distribution of the inferotemporal branch retinal artery was revealed by color fundus photograph of the left eye (Fig. 1). Delayed arterial filling corresponding to the area of retinal edema in the early phase and capillary nonperfusion around the optic disc, leakage at the posterior pole in the late phase were revealed by ultra-widefield fluorescein angiography (UWFA) (Fig. 2). Hyper-reflective band in the inner plexiform and inner nuclear layers and

\begin{tabular}{lll} 
Table 1 Systemic examination parameters of the patient \\
\hline Characteristic & Measured value & Reference values \\
Blood pressure $(\mathrm{mmHg})$ & $135 / 85$ & $<140 / 90$ \\
Pulse rate $(/ \mathrm{min})$ & 88 & $60-100$ \\
Axillary body temperature $\left({ }^{\circ} \mathrm{C}\right)$ & 36.2 & $36-37$ \\
FBG $(\mathrm{mmol} / \mathrm{L})$ & $6.78^{\mathrm{a}}$ & $3.9-6.1$ \\
$\mathrm{HbA1c}(\%)$ & $6.4^{\mathrm{a}}$ & $4.0-6.0$ \\
WBC $\left(10^{9} / \mathrm{L}\right)$ & $12.93^{\mathrm{a}}$ & $3.5-9.5$ \\
$\mathrm{RBC}\left(10^{12} / \mathrm{L}\right)$ & $6.23^{\mathrm{a}}$ & $4.3-5.8$ \\
$\mathrm{HB}(\mathrm{g} / \mathrm{L})$ & $180^{\mathrm{a}}$ & $130-175$ \\
$\mathrm{PLT}\left(10^{9} / \mathrm{L}\right)$ & 276 & $125-350$ \\
PCV $(\%)$ & $52.4^{\mathrm{a}}$ & $40-50$ \\
$\mathrm{CRP}(\mathrm{mg} / \mathrm{L})$ & 0.5 & $0.0-8.0$ \\
PT(S) & $10.4^{\mathrm{a}}$ & $11.0-14.0$ \\
PT\% (\%) & $127^{\mathrm{a}}$ & $66-110$ \\
\hline
\end{tabular}

FGB Fasting blood glucose, WBC White blood cell, $R B C$ Red blood cell, $H B$ Hemoglobin, PLT platelet, PCV Packed cell volume, CRP C-reactive protein, PT Prothrombin time. ${ }^{a}$ measured values are out of reference values. thickening of the retinal layers were shown by spectraldomain optical coherence tomography (SD-OCT) (Fig. 3). Central scotomas corresponding to the area of BRAO in the left eye were shown in the Humphrey visual field (Fig. 4).

The HBO treatment, which included daily sessions lasting for $110 \mathrm{~min}$ at 2.0 absolute atmospheres, was performed for 10 days. The BCVA in the left eye on the fourth and sixth day of the HBO treatment were 20/33 and $20 / 25$, respectively. On the first day after the end of the HBO treatment, the BCVA in the left eye was $20 / 20$, and it remained unchanged at 1 month after the $\mathrm{HBO}$ treatment. Superficial retina whitening of the left eye disappeared, which was revealed by color fundus photograph (Fig. 1). The narrowing of the hyper-reflective band and the thinning of the retinal layers were shown in SD-OCT (Fig. 3). Central scotomas of the Humphrey visual field had become smaller in the left eye (Fig. 4).

\section{Discussion and conclusions}

Currently, there are only a few reports on retinal artery occlusion secondary to high-altitude exposure. A case of central retinal artery occlusion secondary to bilateral buried optic nerve drusen at high altitude was reported in 1995 [5], while another case of central retinal artery occlusion caused by the expansion of intraocular gas during mountain travel at high altitude was reported in 2002 [6]. A recent report has shown that cilioretinal artery occlusion and related central retinal vein occlusion occurred as a complication following high-altitude exposure [7]. It has been speculated that the reason for a few reports of retinal artery occlusion secondary to highaltitude exposure might be that some clinicians do not master the pathogeny of retinal vascular occlusion, thus do not inquire the patient's travel history or consider high altitude as a risk factor. Possible reasons for retinal artery occlusion secondary to high-altitude exposure may be related to hematocrit, hemoglobin concentration, and blood viscosity that were all increased in the hematologic examination of high-altitude climbers, which indicated the higher coagulative activity, as the present case shown [1]. The patient was in a state of hypercoagulability. The atmospheric pressure decreases along with the increase of the altitude, after which the retinal arteries and veins tend to dilate. Retinal vascular occlusion in patients with circulatory impairment has been shown to be triggered by reactive vasoconstriction, which may occur during the descent [8]. Furthermore, hypoxia has an important role in the development of retinal artery occlusion. Hypobaric hypoxia caused thrombosis, which further decreased the oxygen transport capacity. The patient, in our case began to experience disturbances at low altitude after the end of his journey. It is possible that reactive vasoconstriction and hypoxia 


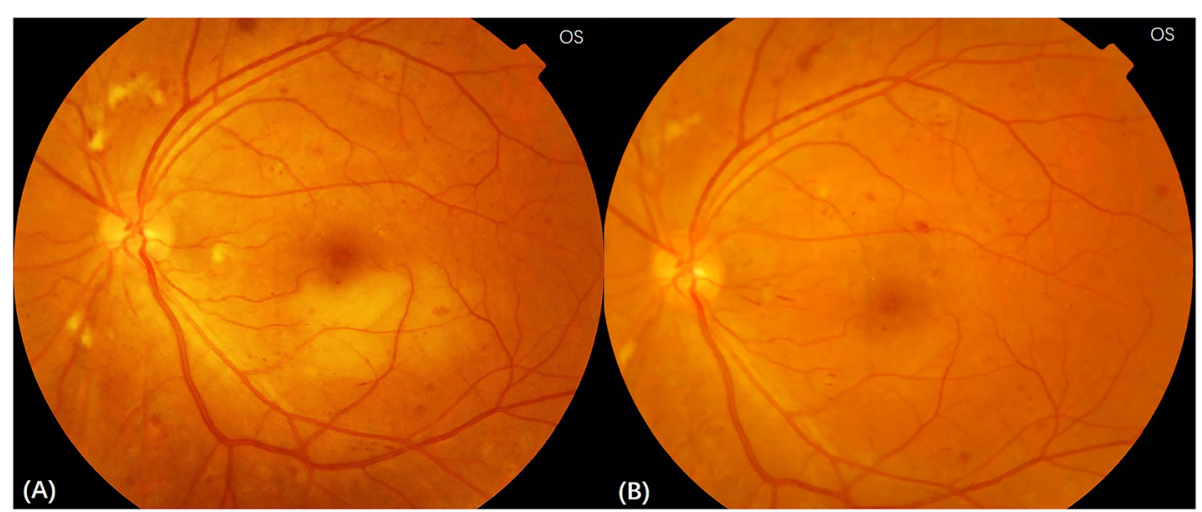

Fig. 1 a Color fundus photograph of the left eye showing an area of superficial retinal whitening inferior to the fovea along the distribution of the inferotemporal branch retinal artery before the HBO treatment. b Color fundus photograph of the left eye showing superficial retina whitening disappeared after the HBO treatment

injury of capillary endothelium may be the cause of the delayed vasculopathy [9].

Furthermore, there are few reports on cases with BRAO secondary to DR even in the absence of highaltitude exposure. Arterial attenuation, which is an important sign of retinal artery occlusion, is widely present in patients with DR, particularly in patients with panretinal photocoagulation [10]. Accordingly, it is difficult to detect retinal artery occlusion in patients with DR. As shown in our case, characteristics of BRAO were atypical in fluorescein angiography. The arterial lumen in patients with DR was less elastic and smaller, thus making emboli easier to be trapped [10]. Consequently, retinal artery occlusion is more likely to happen. On the other hand, patients with diabetes are more likely to have thrombosis [11]. In addition, patients with diabetes may suffer from the underlying ocular ischemic syndrome. In the present case, multiple carotid atherosclerotic plaques
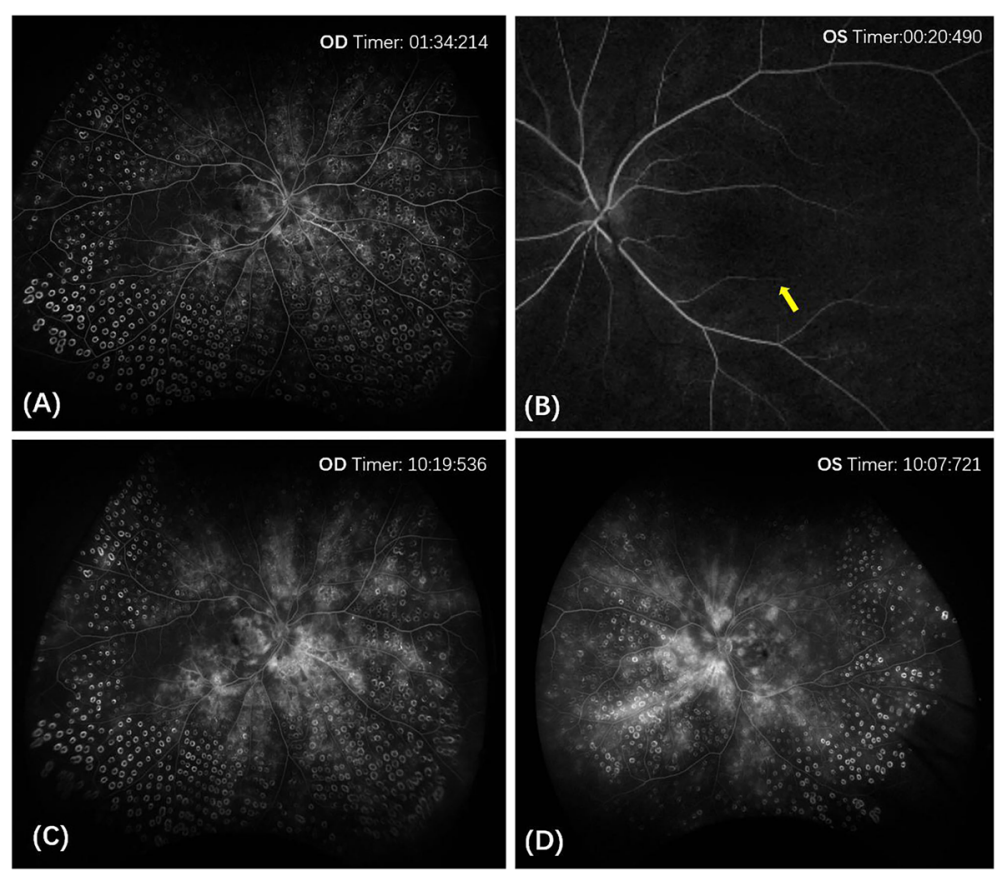

Fig. 2 (a, right eye; $\mathbf{b}$, left eye) Ultra-widefield fundus fluorescein photographs, the yellow arrow in image B indicating delayed arterial filling corresponding to the area of retinal edema in the early phase. (C, right eye; D, left eye) Ultra-widefield fundus fluorescein photographs showing capillary nonperfusion around the optic disc and leakage at the posterior pole in the late phase 


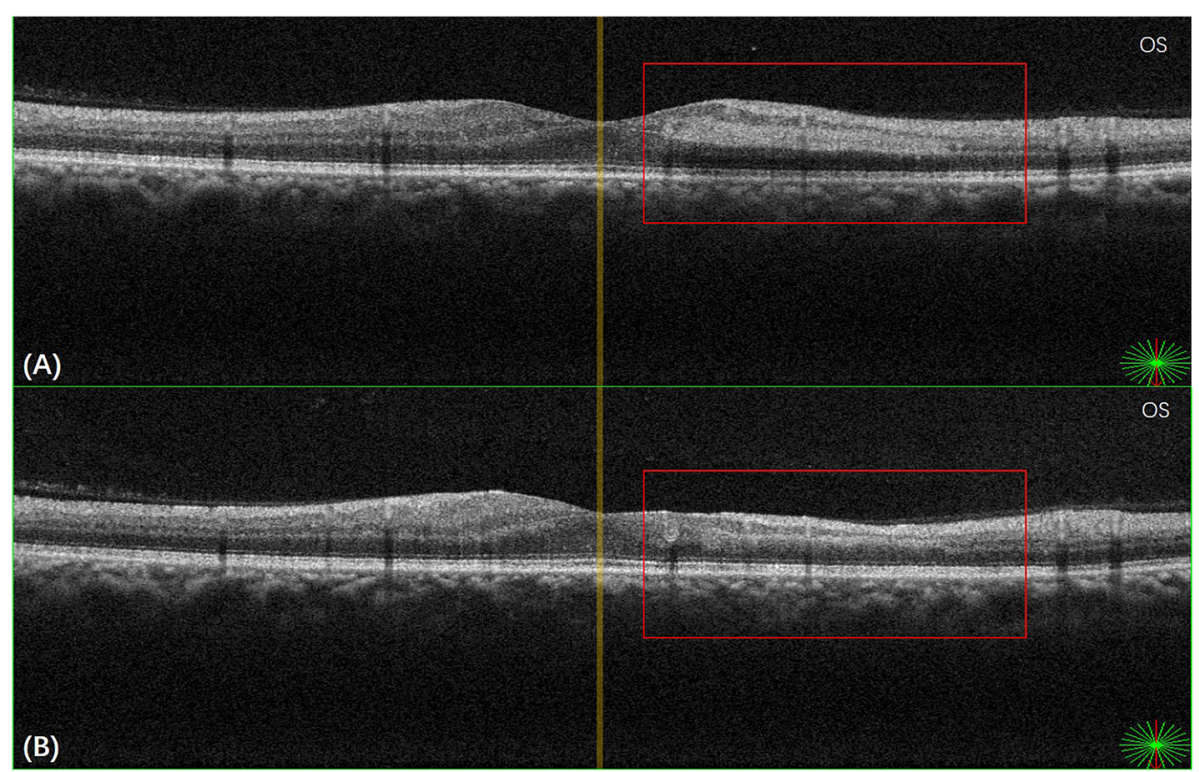

Fig. 3 a OCT scan of the left eye showing hyper-reflective band in the inner plexiform and inner nuclear layers and thickening of the retinal layers before the $\mathrm{HBO}$ treatment. $\mathbf{b} \mathrm{OCT}$ scan of the left eye showing the narrowing of hyper-reflective band and the thinning of the retinal layers after the HBO treatment

were shown by the Doppler examination. It is possible that when the central artery perfusion pressure is low, and without any emboli, the blood vessels tend to close more easily [12]. In addition, local choroidal circulation was damaged by previous panretinal photocoagulation [13]. The development of ocular ischemic syndrome may be aggravated by choroidal ischemia, which cannot be detected by fluorescein angiogram or by carotid artery doppler.

What happens to the retina of patients with DR exposed to high altitude? Both DR and high-altitude exposure are risk factors of BRAO, so there could be a

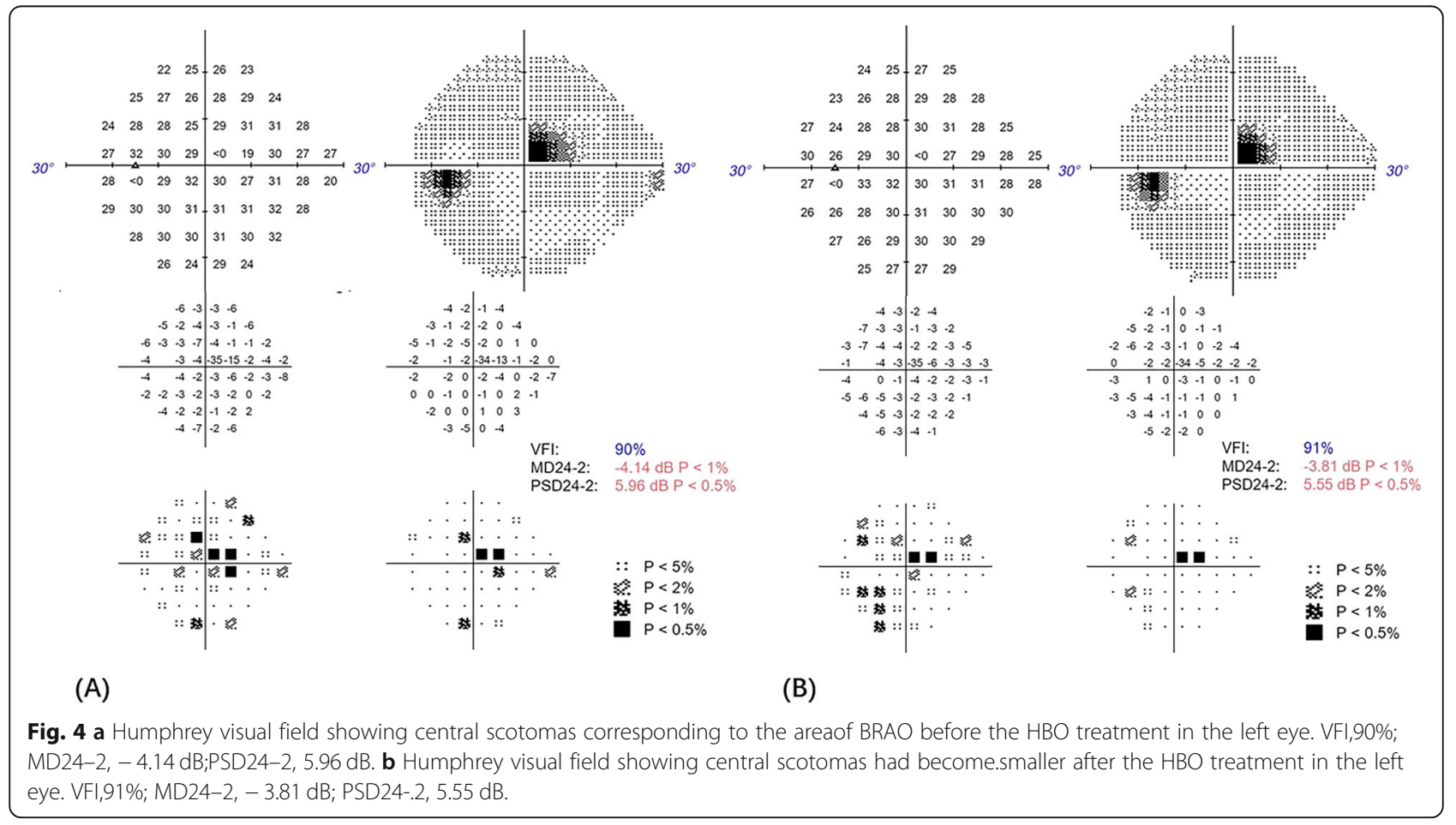


synergistic effect between the two conditions [14]. A previous study has shown that acute high-altitude exposure-related hypoxia leads to a slight increase in central retinal thickness [15]. Another research has reported that high-altitudes exposure may accelerate the development of DR in athletes [16]. The patient, in our case, had diabetes for 10 years. Subtotal panretinal photocoagulation was performed before his high-altitude journey to Tibet. Blood glucose was not monitored during the journey. It is speculated that DR and highaltitude exposure had a synergistic effect on the occurrence of BRAO. The BRAO occurred in the left eye with relatively severe DR, not in the right eye with mild DR. Leal's study [17] showed that in the development of DR, basal membrane thickening can contribute to vascular occlusion and retinal hypoxia. These conclusions need to be confirmed by further prospective research.

Previous studies have shown that HBO treatment is a safe, manageable, low-cost, and effective treatment for retinal artery occlusion [7]. HBO treatment have an effect on visual outcome in patients with BRAO [18]. HBO treatment causes an increased solubility of oxygen of the blood (from 0.3 up to $6 \mathrm{vol} \%$ ) [19], which is important for the choroidal vasculature delivering more oxygen to the retinal [20]. Retinal circulation perfusion could be increased by $\mathrm{HBO}$ treatment. Intraocular pressure and scleral vein pressure could also be decreased by HBO treatment, and then thrombus could be moved to a further location [21].. A previous study showed that HBO treatment had been used for diabetic macular edema [14]. As our case shown, the subjective symptom such as visual acuity was improved after HBO treatment. Central scotomas of the visual field had become smaller after the HBO treatment, however learning also could contribute to the changes of the visual field. Objectively, the changes in fundus appearance and SD-OCT may reflect the natural history of the disease, not only the effects of HBO treatment. Prospective randomized controlled trials are needed to further confirm the actual improvement of $\mathrm{HBO}$ treatment. Long-term effects of $\mathrm{HBO}$ treatment on patients with BRAO need to be confirmed by follow-up.

In summary, high-altitude exposure and DR may be considered as relevant risk factors to BRAO. The ophthalmologist should be aware that the BRAO may be a rare presenting sign of the HAR, particularly in patients with DR. HBO treatment can be considered as a choice for ophthalmologists on treatment against BRAO.

\section{Abbreviations}

BCVA: Best corrected visual acuity; BRAO: Branch retinal artery occlusion; CRP: C-reactive protein; DR: Diabetic retinopathy; FGB: Fasting blood glucose; HAR: High altitude retinopathy; HB: Hemoglobin; HBO: Hyperbaric oxygen; PCV: Packed cell volume; PLT: Platelet; PT: Prothrombin time; RBC: Red blood cell; SD-OCT: Spectral domain optical coherence tomography; UWFA: Ultrawidefield fluorescein angiography; WBC: White blood cell

\section{Acknowledgements}

Not applicable.

\section{Authors' contributions}

XF performed a background search of the literature and drafted the manuscript. LW conceived of this case report. HW contributed to the acquirement of the results of the routine examinations of ophthalmology and the images of visual field. JZ and $\mathrm{HQ}$ analyzed and interpreted the patient data regarding ophthalmological exams. YW contributed to the whole management. All authors have read and approved the final manuscript.

\section{Funding}

This work was supported by Capital's Funds for Health Improvement and Research (NO.2018-1-2021). This funding supports the cost of the collection of data and the publication of the manuscript.

\section{Availability of data and materials}

The datasets used and/or analyzed during the current study are available from the corresponding author on reasonable request.

Ethics approval and consent to participate

Not applicable.

\section{Consent for publication}

Written informed consent was obtained from the patient.

\section{Competing interests}

The authors declare that they have no competing interests.

\section{Author details}

'Department of Ophthalmology, Beijing Friendship Hospital, Capital Medical University, NO.95 Yong'an Road, Xicheng District, Beijing 100050, China. 2Department of Ophthalmology, Beijing Moslem People's Hospital, Beijing, China. ${ }^{3}$ Department of Ophthalmology, Fuxing Hospital, Capital Medical University, Beijing, China. ${ }^{4}$ Department of Ophthalmology, Peking University Third Hospital, Beijing, China.

Received: 1 April 2020 Accepted: 8 July 2020

Published online: 11 July 2020

\section{References}

1. Bhende MP, Karpe AP, Pal BP. High altitude retinopathy. Indian J Ophthalmol. 2013;61(4):176-7.

2. Clarke AK, Cozzi M, Imray CHE, Wright A, Pagliarini S. Analysis of retinal segmentation changes at high altitude with and without acetazolamide. Invest Ophthalmol Vis Sci. 2019;60(1):36-40.

3. Russo A, Agard E, Blein JP, Chehab HE, Lagenaite C, Ract-Madoux G, Dot C. High altitude retinopathy: report of 3 cases. J Fr Ophtalmol. 2014;37(8):629-34

4. Morris DS, Somner J, Donald MJ, McCormick IJ, Bourne RR, Huang SS, Aspinall P, Dhillon B. The eye at altitude. Adv Exp Med Biol 2006; 588: 249-270.

5. Newsom RS, Trew DR, Leonard TJ. Bilateral buried optic nerve drusen presenting with central retinal artery occlusion at high altitude. Eye (Lond) 1995;9(Pt 6):806-8.

6. Fang IM, Huang JS. Central retinal artery occlusion caused by expansion of intraocular gas at high altitude. Am J Ophthalmol. 2002;134(4):603-5.

7. Gokce G, Metin S, Erdem U, Sobaci G, Durukan AH, Cagatay HH, Ekinci M. Late hyperbaric oxygen treatment of cilioretinal artery occlusion with nonischemic central retinal vein occlusion secondary to high altitude. High Alt Med Biol. 2014;15(1):84-8.

8. Willmann G, Fischer MD, Schommer K, Bartsch P, Gekeler F, Schatz A. Missing correlation of retinal vessel diameter with high-altitude headache. Ann Clin Transl Neurol. 2014;1(1):59-63.

9. Barthelmes D, Bosch MM, Merz TM, Petrig BL, Truffer F, Bloch KE, Holmes TA, Cattin P, Hefti U, Sellner M, et al. Delayed appearance of high altitude retinal hemorrhages. PLoS One. 2011;6(2):e11532.

10. Chen SN, Chao CC, Hwang JF, Yang CM. Clinical manifestations of central retinal artery occlusion in eyes of proliferative diabetic retinopathy with previous vitrectomy and panretinal photocoagulation. Retina. 2014;34(9): $1861-6$. 
11. Hayreh SS, Podhajsky PA, Zimmerman MB. Retinal artery occlusion: associated systemic and ophthalmic abnormalities. Ophthalmology. 2009; 116(10):1928-36

12. Mazlout H, Trojet S, Toumi A, Kefi S, Ben Kacem K, Nouhaili H, Dkhillali R, Afrit MA, Kraiem A. Central retinal vein occlusion and internal carotid artery hypoplasia: a case report. J Fr Ophtalmol. 2010;33(1):52 e1-5.

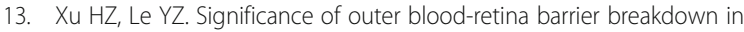
diabetes and ischemia. Invest Ophthalmol Vis Sci. 2011;52(5):2160-4.

14. Arjamaa O, Nikinmaa M. Oxygen-dependent diseases in the retina: role of hypoxia-inducible factors. Exp Eye Res. 2006;83(3):473-83.

15. Fischer MD, Willmann G, Schatz A, Schommer K, Zhour A, Zrenner E, BartzSchmidt KU, Gekeler F. Structural and functional changes of the human macula during acute exposure to high altitude. PLoS One. 2012;7(4):e36155.

16. Sayarlioglu H, Erkoc R, Dogan E, Topal C, Algun E, Erem C, Atmaca H, Kocak E, Yilmaz R, Erdol H, et al. Nephropathy and retinopathy in type 2 diabetic patients living at moderately high altitude and sea level. Ren Fail. 2005; 27(1):67-71.

17. Leal C, Admetlla J, Viscor G, Ricart A. Diabetic retinopathy at high altitude. High Alt Med Biol. 2008;9(1):24-7.

18. Schmidt I, Walter P, Siekmann U, Plange N, Koutsonas A, Mazinani BE, Kuerten D. Development of visual acuity under hyperbaric oxygen treatment $(\mathrm{HBO})$ in non arteritic retinal branch artery occlusion. Graefes Arch Clin Exp Ophthalmol. 2020;258(2):303-10.

19. Piantadosi CA. Physiology of hyperbaric hyperoxia. Respir Care Clin N Am. 1999:5(1):7-19.

20. Carlisle R, Lanphier EH, Rahn H. Hyperbaric oxygen and persistence of vision in retinal ischemia. J Appl Physiol. 1964;19:914-8.

21. Weiss JN. Hyperbaric oxygen treatment of nonacute central retinal artery occlusion. Undersea Hyperb Med. 2009;36(6):401-5.

\section{Publisher's Note}

Springer Nature remains neutral with regard to jurisdictional claims in published maps and institutional affiliations.

Ready to submit your research? Choose BMC and benefit from:

- fast, convenient online submission

- thorough peer review by experienced researchers in your field

- rapid publication on acceptance

- support for research data, including large and complex data types

- gold Open Access which fosters wider collaboration and increased citations

- maximum visibility for your research: over $100 \mathrm{M}$ website views per year

At $\mathrm{BMC}$, research is always in progress.

Learn more biomedcentral.com/submissions 